\title{
Economic effects of interventions to reduce obesity in Israel
}

\author{
Gary M Ginsberg ${ }^{1 *}$ and Elliot Rosenberg ${ }^{2}$
}

\begin{abstract}
Background: Obesity is a major risk factor for many diseases. The paper calculates the economic impact and the cost per Quality-Adjusted Life Year (QALY) resulting from the adoption of eight interventions comprising the clinical and part of the community components of the National Prevention and Health Promotion Program (NPHPP) of the Israeli Ministry of Health $(\mathrm{MOH})$ which represents the obesity control implementation arm of the MOH Healthy Israel 2020 Initiative.
\end{abstract}

Methods: Health care costs per person were calculated by body mass index (BMI) by applying Israeli cost data to aggregated results from international studies. These were applied to BMI changes from eight intervention programmes in order to calculate reductions in direct treatment costs. Indirect cost savings were also estimated as were additional costs due to increased longevity of program participants. Data on costs and QALYs gained from Israeli and International dietary interventions were combined to provide cost-utility estimates of an intervention program to reduce obesity in Israel over a range of recidivism rates.

Results: On average, persons who were overweight $(25 \leq \mathrm{BMI}<30)$ had health care costs that were $12.2 \%$ above the average health care costs of persons with normal or sub-normal weight to height ratios $(\mathrm{BMI}<25)$. This differential in costs rose to $31.4 \%$ and $73.0 \%$ for obese and severely obese persons, respectively.

For overweight $(25 \leq \mathrm{BMl}<30)$ and obese persons $(30 \leq \mathrm{BMl}<40)$, costs per person for the interventions (including the screening overhead) ranged from 35 NIS for a community intervention to 860 NIS, reflecting the intensity of the clinical setting intervention and the unit costs of the professionals carrying out the intervention [e. g., dietician]. Expected average BMI decreases ranged from 0.05 to 0.90 . Higher intervention costs and larger BMI decreases characterized the two clinical lifestyle interventions for the severely obese (BMI $\geq 40$ ).

A program directed at the entire Israeli population aged 20 and over, using a variety of eight different interventions would cost 2.07 billion NIS overall. In the baseline scenario (with an assumed recidivism rate of 50\% per annum), approximately 620,000,000 NIS would be recouped in the form of decreased treatment costs and indirect costs, increased productivity and decreased absenteeism. After discounting the 89,000,000 NIS additional health costs attributable to these extra life years, it is estimated that the total net costs to society would be 1.55 billion NIS. This total net cost was relatively stable to increases in the program's recidivism rates, but highly sensitive to reductions in recidivism rates.

Under baseline assumptions, implementation of the cluster of interventions would save 32,671 discounted QALYs at a cost of only 47,559 NIS per QALY, less than half of the Israeli per capita GNP (104,000 NIS). Thus implementation of these components of the NPHPP should be considered very cost-effective.

Conclusion: Despite the large costs of such a large national program to control obesity, cost-utility analysis strongly supports its introduction.

\footnotetext{
* Correspondence: gary.ginsberg@moh.health.gov.il

'Medical Technology Assessment Sector, Ministry of Health, Ben Tabai 2,

Jerusalem, Israel

Full list of author information is available at the end of the article
}

(C) 2012 Ginsberg and Rosenberg; licensee BioMed Central Ltd. This is an Open Access article distributed under the terms of the Creative Commons Attribution License (http://creativecommons.org/licenses/by/2.0), which permits unrestricted use, distribution, and reproduction in any medium, provided the original work is properly cited. 


\section{Background}

The increasing prevalence of obesity is an important public health problem that contributes to excess morbidity and mortality world-wide [1,2]. Obesity $(30<$ $\mathrm{BMI})$, and overweight $(25<\mathrm{BMI}<30)$ are major risk factors for morbidity and mortality. Calculations based on disease and gender specific relative risks from a recent meta-analysis of internationally published data [3] adjusted to Israeli demographic data, estimated that obesity and overweight and account for around 3,105 deaths $(95 \%$ CI $2,415-4,266)$ per year in Israel $(7.7 \%$ of all deaths). After adapting Canadian Cost of Illness [4] data to Israeli economic conditions, the costs of treating morbidity due to obesity and overweight in Israel amount to NIS 1.92 billion (95\%CI: 4.29-8.33), equal to $0.24 \%$ (95\% CI $0.18 \%-0.35 \%$ ) of the GDP, or $3.05 \%$ (95\% CI 2.29\%-4.45\%) of Israel's health expenditures. Additional costs of NIS 1.89 billion have been estimated to be due to productivity losses, and a further NIS 1.95 billion results from other indirect costs.. Thus the total costs attributable to obesity and overweight amount to approximately NIS 5.76 (95\%CI: $4.29-8.33)$, equal to about $0.73 \%$ (95\%CI $0.54 \%-1.05 \%)$ of the Israeli GDP.

In 2005, the Ministry of Health established the Healthy Israel 2020 initiative to develop a national preventive health targeting program for Israel. Twenty committees covering a broad spectrum of health domains were formed. The Health Behaviors Committee created eight subcommittees, each dealing with key lifestyle behavior risks such as obesity, tobacco use and sedentariness, among others. Health burden-based objectives, quantifiable targets, and science-based and practicable interventions were selected to reduce the respective health (and economic) burdens. A National Prevention and Health Promotion Program (NPHPP) to control obesity, encourage healthful nutrition, and enhance physical activity has been jointly developed by the Ministries of Health, Education, and Culture \& Sports.

The NPHPP interventions to prevent and control obesity can be broadly grouped into three domains:

A. The clinical sphere. Examples include screening, counseling, and medical interventions [such as the prescription of Orlistat, the only currently certified weight loss medication], as well as surgical interventions

B. The community. Examples include home, school, workplace, restaurant and supermarket- based interventions, media strategies, and other initiatives initiated by community-based organizations such as municipal governments and NGO's
C. The legislative sphere. Examples include taxation of unhealthful food products [5], provision of government subsidies to reduce the price of healthful foods [and vice-versa] [6], mandatory food labeling [7], and prohibiting the sale of unhealthful foods in vending machines $[8,9]$.

Nationwide community or clinic-based interventions to reduce obesity can be costly due to the large numbers of people targeted. These high intervention costs form a barrier to the adoption of such programs by government funding agencies (e.g., Ministries of Finance). However, adoption of such programs have the potential not only to generate additional QALYs (quality adjusted life years) but to also reduce treatment costs for diseases directly associated with obesity (e.g., diabetes, hypertension, etc.). In addition, it is likely that further savings will accrue due to productivity gains secondary to decreased presenteeism and absenteeism. Further monetary savings should accrue on account of reduced costs of informal care givers in the community, delayed burial costs, and other indirect costs.

While adding extra QALYs is of paramount importance, interventions that are cost-saving (viz., averted direct and indirect costs exceed intervention costs) or whose net cost (i.e., intervention cost less direct and indirect savings) is low are the ones more likely to be funded.

Recent publications [10-12] have prioritized these interventions by calculating their cost-effectiveness ratios in the form of costs per QALY.

On the other hand, cost-effectiveness analyses of fiscal incentives such as subsidizing healthful foods or taxing unhealthful ones and legislative interventions such as food labeling or banning the sale of unhealthful products in school vending machines were not found in the international scientific literature.

This study then seeks to calculate the expected costs and cost-utility of the implementation of various clinical and community-based intervention strategies forming part of the interventional suite currently recommended by the tri-ministerial NPHPP to reduce the burden of obesity in Israel.

\section{Methods}

\section{Calculation of excess health costs by BMI category}

Sixteen studies from various countries and time periods that reported on the relationship between Body Mass Index (BMI) and health service expenditures [13-28] were identified. The reported data were interpolated and indexed to a standard scale where an average normal BMI value of 22.5 was given an index value of 100 . The average of each BMI specific value was then taken to 
provide a combined index relating health service expenditures with BMI levels.

The BMI prevalence distribution for adults aged 20 and above [Personal Communication, Dr Tami Shohat, Israel Centre for Disease Control] was multiplied by the total adult population aged 20 and above in 2010 of $4,835,024$ persons $[29,30]$ in order to estimate the number of adults within each unit BMI category.

The estimated total of 1.92 billion NIS additional health care costs attributable to obesity (1,145 million NIS) and overweight (773 million NIS) were distributed over the entire BMI spectrum in proportion to the number of persons and the excess health care costs in each BMI unit category. Both total costs and average costs per person in each BMI category were calculated, enabling us to calculate the marginal change in health care costs per unit change in BMI. All costs are presented in New Israeli Shekels (NIS) at mid-2010 price levels (Exchange rate 3.729 NIS to the US dollar).

\section{Allocation of persons to cost-saving and very cost- effective interventions}

All eight office-based and community and dietary interventions [10,31-34] that had been identified as being either cost-saving or very cost-effective in a previous comprehensive study of the cost-utility of interventions [10] were selected in order to estimate their impact on costs when implemented on a national level as part of the NPHPP. Brief descriptions of the interventions are provided in Appendix 1. Two studies that had been identified as being very cost-effective were not included among the eight selected studies on the grounds that one [35] was based on the combined results of a prior included study [32] and the other was based in a clinical drug trial setting [36] that cannot be replicated in routine public health interventions.

It was assumed that the 52,517 severely obese (BMI $\geq$ 40) persons would be allocated equally between the standard and low carbohydrate dietary interventions [34]. The remaining 4,782,506 persons in the population would be distributed equally (i.e., 797,084 persons per intervention) among each of the other six interventions. Therefore we are creating an estimate based on the assumption that Israel adopts a multiplicity of interventions (that have previously succeeded abroad) in equal numbers.

In the intervention where initial screening costs for identifying persons who were overweight or obese were omitted [33], a cost of 5.4 NIS per person screened was added, based on the estimated Israeli costs of three minutes screening time $(50 \%$ by physicians and $50 \%$ by nurses) [10] Full details of the intervention specific cost and QALY estimates are given in our companion source paper [10].

\section{Costs per QALY definitions}

The costs of the interventions were adjusted to Israeli NIS by the country-specific consumer price index to 2010 price levels and by the appropriate exchange rate which took into account purchasing power parities (PPP) for the non-tradable [e.g., manpower] elements of the interventions. Costs per QALY gained were calculated by indexing the results of a prior comprehensive cost-utility study based on 2008 price levels [10] to 2010 price levels [30]. An intervention was defined as being cost-saving if it yields actual savings as well as contributing additional QALYs, very cost-effective if the cost per QALY is less than the Israeli per capita GNP of NIS 104,161 in 2010 [37] or cost-effective [if the cost per QALY is between 1-3 times the per capita GNP (NIS $104,161-312,483)$. If the cost per QALY is more than three times the GNP per capita (> NIS 312,483) then the intervention is regarded as not being cost-effective.

\section{Calculation of treatment cost savings by BMI level}

Total (gross) intervention costs were calculated by multiplying the numbers targeted by the unit costs of the intervention, thereby implicitly assuming an ideal coverage rate of $100 \%$. Absolute effects of the interventions on BMI were calculated directly from the specific study reports on changes in BMI $[18,32,33]$, or indirectly via weight changes [35] and QALYS lost from morbidity due to elevated BMI [10]. Lifetime savings in health treatment costs by intervention were based on the marginal health care costs saved per BMI change multiplied by the intervention-specific BMI change. Future years' savings in health expenditures were calculated using a $3 \%$ per annum discount rate.

There is a paucity of data on long-term recidivism rates after the cessation of intervention programs against obesity. The efficacy data in the studies that were used in this paper were based on intervention studies of up to only one year duration, with modeling techniques in some studies extrapolating the outcomes over longer periods of time.

A baseline $50 \%$ per annum recidivism rate, was selected (with a sensitivity analysis performed in the range of $20 \%-80 \%$ per annum) as a conservative estimate based on the following information:

i) An implied recidivism rate of $4.0 \%$ per annum was derived from a meta-analysis of studies using diet alone, which reported an average weight loss of 4.5 $\mathrm{kg}$ at six months, which was reduced by only $13 \%$ to $3.9 \mathrm{~kg}$ after four years [38].

ii) Studies using diet and exercise reported a $7.9 \mathrm{~kg}$ loss at six months that was reducedby $33 \%$ to $4.5 \mathrm{~kg}$ after four years- implying a $15.0 \%$ recidivism rate [38]. 
iii) The successful maintenance of a weight loss of $7 \%$ or more 2.8 years after an intensive lifestyle intervention by $37 \%$ of overweight individuals with impaired glucose intolerance [39] - implying a recidivism rate of $30.2 \%$.

iv) A reported $13 \%-20 \%$ of persons who maintained a weight loss of at least $5 \mathrm{~kg}$ for five years [40]. This is equivalent to an annual recidivism rate between $33 \%-40 \%$.

v) Data from the US national weight control registry indicate a one-year recidivism rate of 35\% (defined as gaining $2.3 \mathrm{~kg}$ or more), while $59 \%$ maintained their body weight and $6 \%$ continued to loss more weight [41].

vi) Research indicating that approximately $20 \%$ of overweight individuals are successful at long-term weight loss, defined as losing at least $10 \%$ of initial body weight and keeping the weight off for at least one year - implying an $80 \%$ recidivism rate $[40,42]$.

\section{Indirect costs}

Averted productivity losses were based on $98.8 \%$ of estimated direct health care savings [4]. Similarly, averted care costs and other indirect costs were estimated to be $80 \%$ and $22 \%$ of productivity losses [4]. Net costs to society were calculated by deducting all these averted direct and indirect costs from the gross intervention cost. A sensitivity analysis was performed on a range of recidivism rates from $10 \%-90 \%$ per annum.

\section{Converting BMI changes to QALY gains}

BMI unit values were assigned QALY weights by interpolating the values (Table 1) from a UK study [34]. This allowed for marginal QALY improvements per unit decrease in BMI and hence total lifetime QALY gains (discounted at 3\% per annum) and cost per QALY per intervention to be calculated. Additional life expectancy per BMI change (0.415 years per unit BMI) was based on the average value extracted from two studies [33,35] that reported very similar values of an additional 0.41 and 0.42 extra life years per unit BMI decrease, based

\section{Table 1 QALY Weights by BMI Level}

\begin{tabular}{lll}
\hline $\begin{array}{l}\text { BMI (kg/ } \\
\mathbf{m}^{\mathbf{2}} \text { ) }\end{array}$ & Description & $\begin{array}{l}\text { QALY } \\
\text { Weight }\end{array}$ \\
\hline 20 or less & Underweight & 0.741 \\
20 to 24.9 & Desirable & 0.787 \\
25 to 29.9 & Overweight & 0.769 \\
30 to 34.9 & Obese Class I & 0.707 \\
35 to $39.9 \mid$ & Obese Class II & 0.672 \\
$\geq 40$ & Obese Class III (morbidly/extremely & 0.624 \\
& obese) & \\
\hline
\end{tabular}

on reported increased life expectancy and BMI decreases [30] and QALY increases [35]. These intervention specific estimates of increased life expectancy were then converted to QALYs by adjusting by the appropriate Health Adjusted Life Expectancy (HALE) multipliers (that take into account the background decrease in functioning due to aging) and the appropriate BMI to QALY ratio [43].

On an assumption (based on expert opinion as to the ideal age group for intervene with weight control programs) that the average age of a participant in the program was 52 years, and that each had, on average, a residual life expectancy of 30 years [30], we estimated the additional (discounted) health-care costs due to the increased life expectancy of those persons who reduced their BMI.

Excess years gained due to the interventions were assumed to have the characteristic of having average health costs of the treated targeted cohort (i.e., overweight/obese or severely - obese).

\section{Results}

Overweight individuals bore health care costs that were $12.2 \%$ above the those of persons with normal or belownormal weight to height ratios $(\mathrm{BMI}<25)$. This percentage rose to $31.4 \%$ and $73.0 \%$ for obese $(30 \leq$ BMI $<40)$ and severely obese persons $(B M I \geq 40)$, respectively (Table 2). For example, an obese person with a BMI of 37.5 would incur an additional 1,672 NIS in health care expenditures per year. If, however, as a result of participation in an intervention program the person's BMI drops by $1 \mathrm{~kg} / \mathrm{m}^{2}$ to 36.5 , their health expenditures would be expected to fall by 109 NIS (i.e.,: 1,672-1,563) per year (Table 1).

For overweight individuals and obese persons with BMI < 40, costs per person for the interventions (including the screening overhead) ranged from 35 NIS (for a multifaceted community intervention) to 860 NIS (Table 3), for an intensive clinical setting intervention, including the unit costs of the professionals carrying out the intervention (e.g., dietician). The interventions ranged from being cost-saving to being a very cost-effective 50,543 NIS per QALY. Expected average BMI decreases ranged from 0.05 to 0.90 (Table 3). Higher intervention costs, higher costs per QALY, and larger BMI decreases characterized the two clinical lifestyle interventions for the severely obese (BMI $\geq 40$ ) (Table 2 ).

Implementation of the NPHPP to cover the entire Israeli population aged over 20 years with a combination of six different interventions would cost 2.07 billion NIS (Table 4). Approximately 201,000,000 NIS would be recouped in the form of decreased treatment costs and a further 199,000,000 NIS would be regained via increased productivity and decreased absenteeism. Other 
Table 2 Health Care Costs (NIS at 2010 price levels) by BMI

\begin{tabular}{|c|c|c|c|c|c|}
\hline \multirow[t]{2}{*}{ BMI } & \multirow{2}{*}{$\begin{array}{l}\text { Health } \\
\text { Care } \\
\text { Costs } \\
\text { (a) }\end{array}$} & \multirow{2}{*}{$\begin{array}{c}\text { BMI } \\
\text { distribution } \\
\text { (b) }\end{array}$} & \multirow{2}{*}{$\begin{array}{l}\text { Population } \\
\text { (c) }\end{array}$} & \multicolumn{2}{|c|}{$\begin{array}{l}\text { Health Care Costs of } \\
\text { Obesity or Overweight }\end{array}$} \\
\hline & & & & $\begin{array}{c}\text { Total } \\
\text { (d) }\end{array}$ & $\begin{array}{c}\text { per person } \\
\text { (e) }\end{array}$ \\
\hline$<19$ & n.a. & $2.4 \%$ & 115,576 & n.a. & n.a. \\
\hline 19 & $94 \%$ & $2.5 \%$ & 121,863 & 0 & 0 \\
\hline 20 & $96 \%$ & $4.6 \%$ & 220,030 & 0 & 0 \\
\hline 21 & $98 \%$ & $5.3 \%$ & 258,233 & 0 & 0 \\
\hline 22 & $100 \%$ & $7.2 \%$ & 345,761 & 0 & 0 \\
\hline 23 & $103 \%$ & $8.7 \%$ & 420,717 & 0 & 0 \\
\hline 24 & $106 \%$ & $9.8 \%$ & 473,911 & 0 & 0 \\
\hline 25 & $108 \%$ & $9.8 \%$ & 473,427 & $123,593,389$ & 261 \\
\hline 26 & $110 \%$ & $8.9 \%$ & 429,905 & $145,645,761$ & 339 \\
\hline 27 & $112 \%$ & $8.2 \%$ & 395,570 & $156,151,524$ & 395 \\
\hline 28 & $115 \%$ & $7.2 \%$ & 346,729 & $171,456,620$ & 494 \\
\hline 29 & $119 \%$ & $6.0 \%$ & 292,084 & $175,690,848$ & 602 \\
\hline 30 & $123 \%$ & $4.9 \%$ & 238,890 & $196,332,658$ & 822 \\
\hline 31 & $126 \%$ & $3.1 \%$ & 149,911 & $141,832,838$ & 946 \\
\hline 32 & $129 \%$ & $2.4 \%$ & 116,060 & $123,015,268$ & 1060 \\
\hline 33 & $133 \%$ & $2.5 \%$ & 120,412 & $144,311,733$ & 1198 \\
\hline 34 & $137 \%$ & $1.4 \%$ & 66,734 & $88,051,773$ & 1319 \\
\hline 35 & $140 \%$ & $1.5 \%$ & 72,054 & $103,825,223$ & 1441 \\
\hline 36 & $143 \%$ & $1.1 \%$ & 51,117 & $79,881,318$ & 1563 \\
\hline 37 & $146 \%$ & $0.78 \%$ & 37,813 & $63,208,344$ & 1672 \\
\hline 38 & $149 \%$ & $0.39 \%$ & 18,906 & $33,668,568$ & 1781 \\
\hline 39 & $154 \%$ & $0.35 \%$ & 16,806 & $32,499,750$ & 1934 \\
\hline 40 & $158 \%$ & $0.23 \%$ & 11,204 & $23,329,496$ & 2082 \\
\hline 41 & $162 \%$ & $0.12 \%$ & 5,602 & $12,496,246$ & 2231 \\
\hline 42 & $166 \%$ & $0.19 \%$ & 9,103 & $21,657,584$ & 2379 \\
\hline \multirow[t]{2}{*}{$\geq 43$} & $184 \%$ & $0.55 \%$ & 26,609 & $80,664,301$ & 3031 \\
\hline & & $100 \%$ & $4,835,024$ & $1,917,313,242$ & \\
\hline
\end{tabular}

Notes:

(a) Based on the average of sixteen articles [13-28].

(b) Calculations based on Israeli survey data (Personal communication. Dr T. Shohat).

(c) Column (b) multiplied by 4,835,024 persons [29,30] aged over 20

(d) Excess costs ((a) less 100\%) multiplied by population (c) and factors that result in a total of $772,538,141$ NIS and 1,144,775,101 NIS [4] additional health care costs attributable to overweight and obesity, respectively.

(e) Column (d)/Column (c)

averted indirect costs account for the saving of an extra 202,000,000 NIS. The discounted health costs attributable to additional life expectancy as a result of BMI reductions, amount to approximately 89,000,000 NIS. Therefore, the total net costs of the interventions to society will be 1.55 billion NIS.

If the recidivism rate is reduced to $35 \%$ or $20 \%$, net societal costs will fall to 1.35 billion and 0.89 billion, respectively. On the other hand, if recidivism rates reach
$65 \%$ or $80 \%$, net societal costs will increase slightly to 1.67 and 1.74 billion NIS, respectively (Table 5).

In the baseline $50 \%$ recidivism scenario, 32,671 QALYs would be saved by implementing the interventions, at an average cost of 47,559 NIS per QALY (Table 5), less than half the per capita annual GNP [24]. Decreased recidivism rates of $35 \%$ and $20 \%$ will increase the numbers of QALYS saved to 45,567 and 75,150 respectively, and decrease costs per QALY to 29,661 and 11,812 NIS per QALY respectively.

Increased recidivism rates of $65 \%$ and $80 \%$ will decrease the numbers of QALYS saved to 25,464 and 20,862 respectively, while increasing costs per QALY to 65,457 and 83,355 NIS per QALY (Table 5), which are both considered as being very cost-effective ratios.

\section{Discussion}

In the baseline case, assuming an annual recidivism rate of $50 \%$, the total intervention costs of eight weight loss programs aimed at the entire adult population of Israel, amount to 2.07 billion NIS. The costs of such a large program are likely to be spread over a period of time, say five or ten years, due to manpower and budgetary constraints. Approximately $29.1 \%$ of these costs would be offset by averted direct and indirect costs attributable to obesity. However, after treatment costs due to increased longevity are taken into account, these saving would be reduced by only about one-quarter $(24.8 \%)$ of the intervention costs.

Our assumption of $100 \%$ coverage is a reasonable one given Israels small size and universal health insurance coverage. In reality, compliancy with some programs will fall short of $100 \%$, but this has been implicitly recognized in the cost and QALY values taken from the source studies (10).

Our assumption of a continual geometric decrease in recidivism could also be considered as being conservative since weight loss maintenance may get easier over time; after successfully maintaining weight loss for 2-5 years, the chance of long-term success generally increases $[40,41]$.

A sensitivity analysis on recidivism rates showed the total net cost is relatively inelastic with respect to changes in the recidivism rate above the baseline $50 \%$ levels; a $60 \%$ increase in recidivism (increasing the rate from $50 \%$ to $80 \%$ ) only causes a $12 \%$ increase in the net costs to society. However, reducing recidivism by $60 \%$, (reducing the estimate from $50 \%$ to $20 \%$ ), which may be achievable by adding a maintenance component to existing programs, would have a more elastic impact on costs, reducing them by $43 \%$. Sixty percent increases and decreases $n$ recidivism would reduce and increase QALY gains by $44 \%$ and $65 \%$, respectively. 
Table 3 Costs (NIS at 2010 price levels) and Effects of Dietary Interventions to Reduce Obesity.

\begin{tabular}{|c|c|c|c|c|c|c|}
\hline $\begin{array}{l}\text { Intervention (for fuller description } \\
\text { See Appendix 1) }\end{array}$ & Study & Ref & & $\begin{array}{c}\text { Cost } \\
\text { per } \\
\text { Person }\end{array}$ & $\begin{array}{l}\text { Cost } \\
\text { per } \\
\text { QALY }\end{array}$ & $\begin{array}{c}\text { BMI } \\
\text { decrease }\end{array}$ \\
\hline $25 \leq \mathrm{BMI}<40$ & & & & & $(f)$ & \\
\hline \multicolumn{7}{|l|}{ Clinical setting } \\
\hline \multicolumn{7}{|l|}{ Nutritional counseling } \\
\hline Various staff providing nutritional counseling over one year, modeled over lifetime & Ginsberg & [10] & $\begin{array}{l}\text { (a, } \\
\text { d) }\end{array}$ & 57 & 50,543 & 0.05 \\
\hline General practitioner-based nutritional counseling over one year, modeled over lifetime & Olsen & [33] & (c) & 395 & 4,379 & 0.22 \\
\hline Dietician-based nutritional counseling, over one year, modeled over lifetime & Olsen & [33] & (c) & 860 & 31,982 & 0.07 \\
\hline Clinic-based, intensive lifestyle counseling for the obese over 3 years modeled over lifetime & $\begin{array}{l}\text { J-van der } \\
\text { Bruggen }\end{array}$ & [32] & $\begin{array}{l}(c, \\
\text { e) }\end{array}$ & 798 & 26,769 & 0.90 \\
\hline \multicolumn{7}{|l|}{ Combined nutritional counseling and office support } \\
\hline $\begin{array}{l}\text { Counseling by primary care internists trained in nutrition counseling with an office-support } \\
\text { program tracked for one year Cost-utility estimates based on Israeli data }\end{array}$ & Ockene & [31] & $\begin{array}{l}(b, \\
\text { d) }\end{array}$ & 74 & $<0$ & 0.81 \\
\hline \multicolumn{7}{|l|}{ Community setting } \\
\hline $\begin{array}{l}\text { Community-based strategy using mass media campaigns, social support, risk factor screening } \\
\text { and counseling in various settings over } 5 \text { years modeled over lifetime }\end{array}$ & $\begin{array}{l}\text { J-van der } \\
\text { Bruggen }\end{array}$ & [32] & $\begin{array}{l}(c, \\
\text { e) }\end{array}$ & 35 & 19,938 & 0.15 \\
\hline \multicolumn{7}{|l|}{$\mathrm{BMI}>40$} \\
\hline \multicolumn{7}{|l|}{ Clinical setting } \\
\hline $\begin{array}{l}\text { Medical center staff counseling to adhere to a low carbohydrate diet over one year. Time } \\
\text { horizon for cost utility analysis also one year }\end{array}$ & Tsai 2003 & [34] & (c) & 5,767 & 39,591 & 1.59 \\
\hline $\begin{array}{l}\text { Medical center staff counseling to adhere to Standard NCEP } 1 \text { diet }[g] \text { over one year. Time } \\
\text { horizon for cost utility analysis also one year }\end{array}$ & Tsai 2003 & [34] & (c) & 5,584 & 38,759 & 0.97 \\
\hline
\end{tabular}

Notes: CS = Cost Saving

(a) Based on primary Israeli epidemiological, demographic and cost data.

Effectiveness from meta-analysis of international studies.

(b) Based on primary Israeli epidemiological and demographic data.

Cost data updated and converted to Israel 2010 price levels. Effectiveness from international study.

(c) Based on international data converted to Israel 2010 price levels.

(d) Based on cost per QALY at average 10 year AMI risk of $12.8 \%$ at age 55 .

(e) Includes initial screening charge of 5.4 NIS per head [10].

(f) Ref [10] updated to 2010 price levels. All values are ACERs, average cost-effectiveness ratios.

A growing body of literature supports the notion that the factors leading to recidivism may be different and more challenging than those faced during the initial months to one year of weight loss [44]. Therefore the prevention of recidivism merits separate intervention studies (such as maintenance therapy) and cost-effectiveness analyses.

The effectiveness (and resulting cost-effectiveness ratios) generated by the interventions listed in this paper may be overstated or understated. The seven non-

Table 4 Intervention Costs and Savings (at 2010 price levels).

\begin{tabular}{lccccccccc}
\hline & Ref & $\begin{array}{c}\text { Numbers } \\
\text { Targeted }\end{array}$ & $\begin{array}{c}\text { Total } \\
\text { Intervention } \\
\text { Costs }\end{array}$ & $\begin{array}{c}\text { Lifetime } \\
\text { Savings in } \\
\text { Direct Costs } \\
\text { of Illness }\end{array}$ & $\begin{array}{c}\text { Lifetime } \\
\text { Savings in } \\
\text { Productivity } \\
\text { costs }\end{array}$ & $\begin{array}{c}\text { Lifetime } \\
\text { Savings in } \\
\text { Carer } \\
\text { Costs }\end{array}$ & $\begin{array}{c}\text { Lifetime } \\
\text { Savings in } \\
\text { other Indirect } \\
\text { Costs }\end{array}$ & $\begin{array}{c}\text { Medical Costs } \\
\text { due to } \\
\text { increased } \\
\text { longevity }\end{array}$ \\
\hline Ginsberg & & & & & $\begin{array}{c}\text { Net } \\
\text { Costs }\end{array}$ \\
Ockene & 31 & 797,084 & $45,119,420$ & $4,648,779$ & $4,592,029$ & $3,656,496$ & $1,016,092$ & $2,013,874$ & $33,219,898$ \\
J-van der Bruggen I & 32 & 797,084 & $27,975,847$ & $13,176,831$ & $13,015,976$ & $10,364,235$ & $2,880,085$ & $5,708,269$ & $-5,753,012$ \\
J-van der Bruggen II & 32 & 797,084 & $635,754,990$ & $79,060,989$ & $78,095,855$ & $62,185,409$ & $17,280,510$ & $34,249,611$ & $433,381,838$ \\
Olsen I & 33 & 797,084 & $315,120,819$ & $19,714,059$ & $19,473,401$ & $15,506,090$ & $4,308,939$ & $8,540,228$ & $264,658,558$ \\
Olsen II & 33 & 797,084 & $685,335,609$ & $5,877,750$ & $5,805,998$ & $4,623,143$ & $1,284,711$ & $2,546,270$ & $670,290,278$ \\
Tsai I & 34 & 26,259 & $151,434,528$ & $4,611,477$ & $4,555,182$ & $3,627,156$ & $1,007,939$ & $3,427,595$ & $141,060,368$ \\
Tsai II & 34 & 26,259 & $146,623,901$ & $2,803,055$ & $2,768,836$ & $2,204,742$ & 612,669 & $2,083,440$ & $140,318,039$ \\
TOTAL & & $4,835,024$ & $2,066,115,891$ & $201,047,829$ & $198,593,546$ & $158,134,140$ & $43,943,405$ & $89,393,937$ & $1,553,790,908$ \\
\hline
\end{tabular}

Baseline case of $50 \%$ recidivism per year. 
Table 5 Net Costs per QALY of Interventions by Recidivism Rate.

\begin{tabular}{|c|c|c|c|c|c|}
\hline Recidivism Rate & $20 \%$ & $35 \%$ & $50 \%$ & $65 \%$ & $80 \%$ \\
\hline Intervention Costs & $2,066,115,891$ & $2,066,115,891$ & $2,066,115,891$ & $2,066,115,891$ & $2,066,115,891$ \\
\hline \multicolumn{6}{|l|}{ less Savings } \\
\hline Direct Treatment & $-462,448,210$ & $-280,406,001$ & $-201,047,829$ & $-156,699,045$ & $-128,379,941$ \\
\hline Productivity Losses & $-456,802,895$ & $-276,982,958$ & $-198,593,546$ & $-154,786,149$ & $-126,812,748$ \\
\hline Carer Costs & $-363,738,572$ & $-220,553,299$ & $-158,134,140$ & $-123,251,611$ & $-100,977,223$ \\
\hline Other Costs & $-101,078,183$ & $-61,288,872$ & $-43,943,405$ & $-34,250,008$ & $-28,060,247$ \\
\hline plus longevity Costs & $205,623,043$ & $124,679,767$ & $89,393,937$ & $69,674,687$ & $57,082,876$ \\
\hline Total Savings & $-1,178,444,816$ & $-714,551,362$ & $-512,324,983$ & $-399,312,125$ & $-327,147,283$ \\
\hline Net Costs & $887,671,075$ & $1,351,564,529$ & $1,553,790,908$ & $1,666,803,766$ & $1,738,968,608$ \\
\hline QALYS saved & 75,150 & 45,567 & 32,671 & 25,464 & 20,862 \\
\hline Net Costs per QALY & 11,812 & 29,661 & 47,559 & 65,457 & 83,355 \\
\hline
\end{tabular}

Israeli programs were modeled using observations and assumptions germane to the health care systems and cultures in which they were performed. Hence they may not be completely relevant to the Israeli setting. This may even be true to some degree with respect to the lone Israeli-based screening and dietary intervention [10], as it predicated upon a meta-analysis of the effect of interventions on LDL cholesterol in international studies.

On account of the high intervention costs but relatively low cost savings, readers of this study could conceivably decide not to field the proposed suite of interventions. Yet further examination reveals that although only one of the eight interventions is cost-saving [31] the others are all very-cost effective (even when assuming high recidivism rates) and are therefore worth adopting. They compare very favorably with the most cost-effective interventions identified to reduce damage from smoking [11] and to enhance physical activity [12]. In addition, the gain of roughly 32,671 QALYs, which reflects decreases in morbidity and mortality, should be considered a highly desirable benefit of the proposed intervention program.

A recent OECD document confirmed that counseling people at risk in the primary care setting was one of the most effective and cost-effective ways of improving health [45]. If a long-term time perspective is used, other interventions such as school-based interventions, food advertising regulation, worksite interventions, food labeling and mass media campaigns may also be considered cost-effective with respect to their impact on obesity. In addition, fiscal measures, such as taxing unhealthful foods would be a cost-saving intervention that increases quality of life without incurring extra costs to society [5]

Finally it should be emphasized that current international and HI2020/NPHPP recommended interventions for weight loss include both dietary and physical activity (PA) components. A companion study will be addressing the latter, and it is expected that the insights of both studies will be merged to provide comprehensive CUA data for the complete suite of interventions.

\section{Conclusions}

Fielding an eight-pronged combined clinical and community-based dietary interventional program within the context of the National Program for Health Promotion and Prevention would save over thirty-thousand qualityadjusted life-years, and is very cost-effective. Yet implementation would require a substantial long-term monetary investment by the government. The approximations and extrapolations conducted on the basis of non-Israeli data support future studies geared towards the generation of Israeli epidemiologic and cost modeling data. That said, the overall very cost effective cost-utility estimate of this analysis strongly supports the adoption of the proposed national program to combat obesity.

\section{Appendix 1: Dietary interventions \\ Model incorporating Israeli obesity control data}

Ginsberg [10] constructed an intervention model estimating the cost per QALY of dietary interventions [using reductions in LDL-C levels as an intermediate marker] on the basis of primary Israeli data. It was assumed that everyone aged 20 and above [ $\mathrm{n}=$ $4,633,593]$ would have their waist circumference and BMI measured. The $14.8 \%$ [685,772 obese persons] with a BMI $\geq 30$ would then receive dietary counseling. The cost of the dietary intervention was based on the client making two visits during the first three months and then monthly visits thereafter. Based on common Israeli practice, it was assumed that $50 \%$ of the visits would be to a physician, $25 \%$ to a trained nurse, $20 \%$ to a dietician, and the remaining $5 \%$ to a psychologist. 


\section{International interventions adapted to the Israeli setting} In the USA, Ockene [31] evaluated the effect of nutritional counseling offered by primary care internists offered training in nutritional counseling and aided by an office-support program on the saturated fat intake, weight, and serum lipid measurements of hyperlipidemic patients over one year. Net costs per reduction in LDL-C levels were calculated. The model developed for the Israeli dietary intervention [4], was then used to calculate the resultant costs per QALY of the intervention.

Van-der Bruggen's Dutch lifestyle intervention model [32] projected the costs and effects of both a community-based lifestyle program for the general population and an intensive lifestyle intervention for obese adults, implemented in a health care setting.

Olsen's Danish study [33] randomized 60 GPs either to provide nutritional counseling or to refer patients to a dietician for counseling.

\section{Severely Obese}

Tsai et al. compared a low-carbohydrate diet (under 30 grams/day) with the National Cholesterol Education Program Step I low fat diet for treating severe obesity [34] in a medical center setting. Study participants received weekly group counseling sessions during the first month, followed by monthly group sessions for the next five months.

\section{Acknowledgements}

We acknowledge the help of Dr Tami Shohat, Israel Centre for Disease Control, for providing data on the distribution of BMI in Israel.

\section{Author details \\ ${ }^{1}$ Medical Technology Assessment Sector, Ministry of Health, Ben Tabai 2, Jerusalem, Israel. ${ }^{2}$ Healthy Israel 2020 Initiative, Ministry of Health, Pierre Koenig 33, Jerusalem, Israel.}

\section{Authors' contributions}

GMG designed the study, collected the data, carried out the data analysis, wrote the initial and wrote, read and approved the final manuscript. ER contributed to the interpretation of the data, made critical revisions and wrote, read and approved the final manuscript.

\section{Authors' information}

Gary Ginsberg is a health economist, specializing in epidemiologic-economic evaluations (cost-utility analysis), and is the Director of the Medical

Technology Assessment Sector of the Israeli Ministry of Health. He previously worked for the $\mathrm{WHO}, \mathrm{RTI}$ and the London Borough of Wandsworth. Elliot Rosenberg is a physician specializing in General Preventive Medicine and Public Health. His interests lie in national health targeting, clinical preventive medicine, health promotion in the worksite and in elders, and alertness management. He serves as National Coordinator for the Healthy Israel 2020 initiative and is Head of the Department of Occupational Health at the Israeli Ministry of Health and is a member of the Israeli Task Force on Clinical Preventive Services. He served for many years as a career flight surgeon in the Israeli Air Force.

\section{Competing interests}

Both authors are salaried staff of the Ministry of Health and there are no competing interests to declare.
Received: 2 February 2011 Accepted: 18 April 2012

Published: 18 April 2012

\section{References}

1. World Health Organization: Obesity: Preventing and Managing the Global Epidemic WHO, Geneva; 2000, Technical Report Series No. 894

2. Cecchini M, Sassi F, Lauer JA, Lee YY, Guajardo-Barron V, Chisholm D: Tackling of unhealthy diets, physical activity, and obesity: health effects and cost-effectiveness. Lancet 2010, DOI:10.1016/S0140-6736[10]61514.

3. Guh DP, Zhang W, Bansback N, Amarsi Z, Birmingham CL, Anis AH: The incidence of co-morbidities related to obesity and overweight: $A$ systematic review and meta-analysis. BMC Public Health 2009, 9:88.

4. Anis AH, Zhang W, Bansback N, Guh DP, Amarsi Z, Birmingham CL: Obesity and overweight in Canada: an updated cost-of-illness study. Obes Rev 2010, 11:31-40.

5. Sacks G, Veerman JL, Moodie M, Swinburn B: 'Traffic-light' nutrition labelling and 'junk-food' tax: a modelled comparison of costeffectiveness for obesity prevention. Int J Obes (Lond) 2011, 35(7):1001-9.

6. Andreyeva T, Long MW, Brownell KD: The impact of food prices on consumption: a systematic review of research on the price elasticity of demand for food. Am J Public Health 2010, 100:216-22.

7. Dumanovsky T, Huang CY, Bassett MT, Silver LD: Consumer awareness of fast food calorie information in New York City after implementation of a menu labeling regulation. Am J Public Health 2010, 100:2520-5.

8. Park S, Sappenfield WM, Huang Y, Sherry B, Bensyl DM: The impact of the availability of school vending machines on eating behavior during lunch: the Youth Physical Activity and Nutrition Survey. J Am Diet Assoc 2010, 110:1532-6.

9. Fox MK, Dodd AH, Wilson A, Gleason PM: Association between school food environment and practices and body mass index of US public school children. J Am Diet Assoc 2009, 109(2 Suppl):S108-17.

10. Ginsberg G, [in collaboration with Rosenberg E. and Rosen B.]: Cost-Utility Analyses of Interventions to Prevent and Treat Obesity in Israel The Smokler Center for Health Policy Research, RR-550-09, Jerusalem 2010, [http:// brookdale.jdc.org.il/_Uploads/PublicationsFiles/550-10-Obesity-REP-ENG.pdf] Accessed Nov 17th 2010

11. Ginsberg G, Rosen B, Rosenberg E: Cost-Utility Analysis Cost-Utility Analyses of Interventions. to Reduce the Smoking-Related Burden of Disease in Israel. The Smokler Center for Health Policy Research, RR-54010, Jerusalem. 2009, [http://brookdale.jdc.org.il/_Uploads/PublicationsFiles/ 540-10-Reduce-Smoking-REP-ENG.pdf]. Accessed 18th November 2010.

12. Ginsberg G, Rosen B, Rosenberg E: Cost-Utility Analysis Cost-Utility Analyses of Interventions to Increase Exercise in Israeli Adults. The Smokler Center for Health Policy Research, RR-5**-10, Jerusalem 2010 [forthcoming]., [http://brookdale.jdc.org.il/?CategorylD = 192\&ArticlelD].

13. Pronk NP, Goodman MJ, O'Connor PJ, Martinson BC: Relationship between modifiable health risks and short-term health care charges. JAMA 1999, 282:2235-2239.

14. Thompson D, Brown JB, Nichols GA, Elmer PJ, Oster G: Body mass index and future healthcare costs: a retrospective cohort study. Obes Res 2001, 9:210-8.

15. Hu HY, Chou YJ, Chou P, Lee CH, Lee MC, Huang N: Association between obesity and medical care expenditure among Taiwanese adults. Asia Pac J Clin Nutr 2008, 17:492-504.

16. Goetzel RZ, Gibson TB, Short ME, Chu BC, Waddell J, Bowen J, Lemon SC, Fernandez ID, Ozminkowski RJ, Wilson MG, DeJoy DM: A multi-worksite analysis of the relationships among body mass index, medical utilization, and worker productivity. J Occup Environ Med 2010, 52(Suppl 1):S52-8.

17. Heithoff KA, Cuffel BJ, Kennedy S, Peters J: The association between body mass and health care expenditures. Clinical therapeutics 1997, 19:811-820

18. Kuriyama S, Tsuji I, Ohkubo T, Anzai Y, Takahashi K, Watanabe $Y$, Nishino $Y$, Hisamichi S: Medical care expenditure associated with body mass index in Japan: the Ohsaki Study. Int J Obes Relat Metab Disord 2002, 26:1069-74.

19. Counterweight Project Team: Influence of body mass index on prescribing costs and potential cost savings of a weight management programme in primary care. J Health Serv Res Policy 2008, 13:158-66.

20. Wee CC, Phillips RS, Legedza AT, Davis RB, Soukup JR, Colditz GA, Hamel MB: Health care expenditures associated with overweight and obesity among US adults: importance of age and race. Am J Public Health 2005, 95:159-65. 
21. Brown WJ, Hockey R, Dawson AJ: Physical activity, body mass index and health care costs in mid-age Australian women. Aust N Z J Public Health 2008, 32:150-5

22. Cornier M-A, Tate CW, Grunwald GK, Bessesen DH: Relationship between waist circumference, body mass index and medical care costs. Obesity Research 2002, 10:1167-1172.

23. Elmer PJ, Brown JB, Nichols GA, Oster G: Effect of weight gain on medical care costs. Int J Obes Relat Metab Disord 2004, 28:1365-1373.

24. Wang F, McDonald T, Bender J, Reffitt B, Miller A, Edington DW: Association of healthcare costs with per unit body mass index increase. J Occup Environ Med 2006, 48:668-674.

25. Finkelstein EA, Trogdon JG, Cohen JW, Dietz W: Annual medical spending attributable to obesity: payer-and service-specific estimates. Health Aff [Millwood] 2009, 28:w822-31.

26. Finklestein EA, Fiebelkorn IC, Wang G: National medical spending attributable to overweight and obesity: how much, and who's paying? Health All [Millwood] 2003, 22:w 219-26.

27. Arterburn DE, Maciejewski ML, Tsevat J: Impact of morbid obesity on medical expenditures in adults. Int J Obes (Lond) 2005, 29:334-339.

28. Bell JF, Zimmerman FJ, Arterburn DE, Maciejewski ML: Health-Care Expenditures of Overweight and Obese Males and Females in the Medical Expenditures Panel Survey by Age Cohort. Obesity [Silver Spring] 2011, 19(1):228-32

29. Central Bureau of Statistics: Statistical Abstract of Israel No.61 2010. Central Bureau of Statistics, Jerusalem 2010.

30. Central Bureau of Statistics: Monthly Bulletin of Statistics October 2010. Central Bureau of Statistics, Jerusalem; 2010.

31. Ockene IS, Herbert JR, Ockene JK, Saperia GM, Stanek E, Nicolosi R, Merriam PA, Hurley TG: Effect of Physician Delivered Nutrition Counseling Training and Office-support Program on Saturated Fat Intake, Weight, and Serum Lipid Measurements in Hyperlipidemic Populations: Worcester Area Trial for Counseling in Hyperlipidemia [WATCH]. Arch Intern Med 2009, 159:725-731.

32. Jacobs-van der Bruggen MAM, Bos G, Bemelmans WJ, Hoogenveen RT, Vijgen SM, Baan CA: Lifestyle Interventions are Cost-Effective in People with Different levels of Diabetes Risk. Diabetes Care 2007, 30:128-134.

33. Olsen J, Willaing I, Ladelund S, Jorgensen T, Gundgaard J, Sorensen J: CostEffectiveness of Nutritional Counseling for Obese Patients at Risk of Ischemic Heart Disease. Int J Technol Assess Health Care 2005, 21:194-202.

34. Tsai AG, Glick HA, Shera D, Stern L, Samaha F: Cost-Effectiveness of a LowCarbohydrate Diet and a Standard Diet in Severe Obesity. Obesity Research 2005, 13:1834-1840.

35. Bemelmans W, van Baal P, Wenden-Vos W, Schuit J, Freskens E, Ament A, Hoogenveen R: The Costs, Effects and Cost-Effectiveness of Counteracting Overweight on a Population Level. A Scientific Base for Policy Targets for the Dutch National Plan for Action. Preventive Medicine 2008, 46:127-132.

36. Hertzman P: The Cost-Effectiveness of Orlistat in a 1-year WeightManagement Programme for Treating Overweight and Obese Patients in Sweden: a Treatment Responder Approach. Pharmacoeconomics 2005 23:1007-1020.

37. WHO: Macroeconomics and health: investing in health for economic development. Report of the commission on Macroeconomics and health. Geneva: World Health Organization; 2001.

38. Franz MJ, Vanwormer JJ, Crain AL, Boucher JL, Histon T, Caplan W, Bowman JD, Pronk NP: Weight-Loss Outcomes: A systematic Review and Meta-Analysis of Weight-Loss Clinical Trials with a minimum 1-year Follow-Up. J Am Diet Assoc 2007, 107:1755-1767.

39. Knowler WC, Barrett-Connor E, Fowler SE, Hamman RF, Lachin JM Walker EA, Nathan DM, Diabetes Prevention Program Research Group: Reduction in the incidence of type 2 diabetes with lifestyle intervention or metformin. N Engl J Med 2002, 346:393-403.

40. Wing RR, Phelan S: Long-term weight loss maintenance. Am J Clin Nutr 2005, 82(suppl):222S-5S.

41. McGuire MT, Wing RR, Klem ML, Lang W, Hill JO: What predicts weight regain in a group of successful weight losers? J Consult Clin Psychol 1999, 67:177-85.

42. McGuire M, Wing $R$, Hill J: The prevalence of weight loss maintenance among American adults. Int J Obes 1999, 23:1314-9.

43. Sach TH, Barton GR, Doherty M, Muir KP, Jenkinson C, Avery AJ: The Relationship between Body Mass Index and Health-Related Quality of
Life: Comparing the EQ-SD, EuroQol VAS and SF-6D. Int J Obes (Lond) 2005, 31:189-196.

44. Turk MW, Yang K, Hravnak M, Sereika SM, Ewing LJ, Burke LE: Randomized Clinical Trials of Weight-Loss Maintenance: A Review. J Cardiovasc Nurs 2009, 24:58-80.

45. OECD: Healthy Choices, OECD Health Ministerial Meeting, Health System Priorities in the Aftermath of the Crisis. Paris., http://www.oecd.org/ document/16/0,3746,en_21571361_44701414_45642000_1_1_1_1,00.html] Accessed 21st December 2011.

doi:10.1186/2045-4015-1-17

Cite this article as: Ginsberg and Rosenberg: Economic effects of interventions to reduce obesity in Israel. Israel Journal of Health Policy Research 2012 1:17.

\section{Submit your next manuscript to BioMed Central and take full advantage of:}

- Convenient online submission

- Thorough peer review

- No space constraints or color figure charges

- Immediate publication on acceptance

- Inclusion in PubMed, CAS, Scopus and Google Scholar

- Research which is freely available for redistribution

Submit your manuscript at www.biomedcentral.com/submit
C) Biomed Central 